\title{
A EDUCAÇÃO COM BASE EM UMA FORMAÇÃO PARA A EMANCIPAÇÃO: UMA REFLEXÃO
}

\author{
Maria do Rosário Silva Resende*
}

\begin{abstract}
RESUMO
O propósito deste artigo é refletir acerca da educação baseada na formação para a emancipação, tendo a teoria crítica da sociedade como suporte teórico. A sociedade burguesa privou a formação cultural de sua base, ou seja, da apropriação subjetiva da cultura, impedindo a constituição de um indivíduo autônomo, emancipado, surgindo com isso uma pseudoformação, uma perda da capacidade de se fazerem experiências formativas. A educação teria como responsabilidade a produção de uma consciência verdadeira, de uma autoreflexão crítica. Uma educação, portanto, para a contradição e para a resistência, sendo a reflexão e a discussão da formação cultural dos professores fundamentais na busca de uma educação emancipatória.
\end{abstract}

Palavras-chave: formação, cultura, pseudoformação, experiência, indivíduo, autonomia, professores.

Se não fosse pelo temor em ser interpretado equivocadamente como sentimental, eu diria que para haver formação cultural se requer amor; e o defeito certamente se refere à capacidade de amar. Instruções sobre como isto pode ser mudado são precárias. (ADORNO; HORKHEIMER, 1985, p. 64)

\footnotetext{
* Mestre em Educação Escolar Brasileira (FE/UFG) e doutoranda em Psicologia Social (PUC/SP). [e-mail: mrsresende@uol.com.br]
} 
A formação é um tema amplo, profundo e de interesse geral, em especial para aqueles que estão diretamente ligados a instituições educacionais, reconhecidas como locus de formação. Sabe-se, entretanto, e a teoria crítica da sociedade deixa isso claro, que a formação se dá muito além de um espaço educacional. Segundo Adorno, "a formação não é outra coisa do que a cultura pelo lado de sua apropriação subjetiva" (ADORNo, 1972, p. 142). A cultura, porém, não é independente, quer da sociedade, quer da natureza, quer do indivíduo - categorias privilegiadas na teoria crítica. Os nexos estabelecidos entre os conceitos de sociedade, indivíduo, cultura e natureza estão sempre presentes, independentemente de qualquer aspecto que esteja sendo analisado, portanto, seria difícil refletir acerca dessa teoria sem analisar a questão da formação.

Atualmente, fala-se muito em crise de formação cultural. Esta, muitas vezes, é reduzida por pessoas desavisadas às instituições educacionais, responsabilizando-as pela situação em que se encontra a formação no contexto na sociedade.

O que se manifesta como crise da formação cultural não é um simples objeto da pedagogia, que teria que se ocupar diretamente desse fato, mas também não pode se restringir a uma sociologia que apenas justaponha conhecimentos a respeito da formação. Os sintomas de colapso da formação cultural que se fazem observar por toda parte, mesmo no estrato das pessoas cultas, não se esgotam com as insuficiências do sistema e dos métodos da educação, sob a crítica de sucessivas gerações. Reformas pedagógicas isoladas, embora indispensáveis, não trazem contribuições substanciais. Poderiam até, em certas ocasiões, reforçar a crise, porque abrandam as necessárias exigências a serem feitas aos que devem ser educados e porque revelam uma inocente despreocupação diante do poder que a realidade extrapedagógica exerce sobre eles. Igualmente, diante do ímpeto do que está acontecendo, permanecem insuficientes as reflexões e investigações isoladas sobre os fatores sociais que interferem positiva ou negativamente na formação cultural. (ADORNo,1972, p. 141-142)

A formação cultural e até mesmo as teorias pedagógicas apresentam-se tendo como finalidade a constituição de um indivíduo 
autônomo. Porém, pode-se perceber que a racionalidade da dominação da natureza de forma irracional, presente na sociedade burguesa, não permite o surgimento de um indivíduo autônomo, consciente de suas necessidades e de seus fins, pois essa racionalidade impede que ele perceba que é dominado e, em decorrência desse fato, acabe por não vislumbrar a possibilidade de se libertar da dominação.

Adorno (1993, p. 131) afirma em seu livro, Mínima moralia, que

O indivíduo reflete, precisamente em sua individuação, a lei social preestabelecida da exploração, por mais que essa seja mediatizada. Isso significa também que sua decadência na presente fase não é algo a ser derivado de um ponto de vista individual, mas sim a partir da tendência da sociedade, tal como ela se impõe por meio de individuação, e não como mero adversário desta. [...] A sociedade é descrita [...] com um sistema, que não só os encerra [os homens] e [os] deforma, mas penetra até aquela humanidade que um dia os determinava como indivíduos. Através dessa interpretação exclusivamente humana da situação como ela é, a crua realidade material, que conecta o ser humano à desumanidade, se vê aceita mesmo quando é denunciada. [...] A situação na qual o indivíduo desaparece é ao mesmo tempo de um individualismo desenfreado, onde "tudo é possível".

O indivíduo deve ser pensado como uma categoria da sociedade, mediado na origem pela convivência social. Porém, o conceito de indivíduo indica a possibilidade de autodeterminação e autoconsciência do homem, diferenciando-o dessa forma da natureza e da sociedade. Por meio dessa possibilidade existente, o homem traz consigo a antítese da sociedade que o constitui. Assim, sendo o indivíduo entendido como produto e produtor da cultura, ao mesmo tempo, por causa dessa possibilidade de autoconsciência e autodeterminação, acaba contrastando-se com ela.

Tendo em vista que a formação cultural deveria possibilitar a constituição de indivíduos autônomos, e que o processo de formação seria a apropriação subjetiva da cultura, a compreensão da relação entre indivíduo e cultura é importante. Essa relação se dá através da 
constatação das condições objetivas que fazem a mediação, sendo importante refletir acerca do processo cultural que ocorre na sociedade capitalista.

O processo cultural traz em sua base a promessa de gratificação. Esta implica realizações das pulsões, alteradas em sua constituição social e histórica, diante de uma realidade da mesma forma transformada na busca de uma vida melhor para o homem. Porém, pode-se verificar que a cultura tem proporcionado poucos elementos que direcionam para a emancipação humana. As chances humanas de autodeterminação e de autoconsciência são poucas. Desse modo, sem a autonomia que diferencia o indivíduo da natureza, a cultura configura-se como dominação. Portanto, só através da compreensão das condições de perpetuação da dominação, no indivíduo e na cultura, é que se poderá eliminá-la, levando a uma verdadeira formação cultural.

A constituição, ou não, do indivíduo ocorre segundo as necessidades da sociedade. Nesse sentido, uma sociedade regida pelo progresso da dominação, em todas as suas formas, em que o progresso técnico-material é utilizado com o intuito de produzir mais desigualdade e miséria para a maioria dos seus membros, induzindo cada vez mais a barbárie, a formação cultural "se converte em uma pseudoformação socializada, na onipresença do espírito alienado [...] a pseudoformação passou a ser a forma dominante da consciência atual"' (ADORNo, 1972, p. 142). Assim, pode-se afirmar que a crise da formação tão anunciada é uma manifestação da crise social presente na sociedade. Segundo Maar (In: AdORNo, 1995, p. 19), a

crise do processo formativo e educacional [...] é uma conclusão inevitável da dinâmica atual do processo produtivo. E, [...] o conceito de "semiformação" estrutura de dominação. (MAAR, 1995, p. 23)

No ensaio "Teoria de la seudocultura", Adorno aponta que a formação foi uma marca de emancipação da burguesia, como também um privilégio que lhe deu maiores qualificações perante outras pessoas no contexto social. Sem formação, seria impossível os burgueses 
assumirem funções essenciais (empresários, gerentes, funcionários etc.), dentro da estrutura social defendida por eles. Afirma, ainda, que as classes dominantes "monopolizaram a formação cultural numa sociedade formalmente vazia; a desumanização devida ao processo capitalista de produção negou aos trabalhadores todos os pressupostos para a formação" (ADORNo, 1972, p. 148).

Essa negativa é encoberta por uma ideologia cada vez mais radical, escondendo a cisão existente. Esse fato gera o fenômeno da integração (termo sociológico). Assim, vemos que as

[...] barreiras sociais são subjetivamente, para a consciência cada vez mais fluidas [...], e se fornece às massas, através de inúmeros canais, bens de formação cultural que, por estarem neutralizados e petrificados, ajudam a manter-se em sua postura [em seu devido lugar]. (ADORNo, 1972, p. 149-150)

Os produtos da "indústria cultural" 2 são canais importantes que servem para estabelecer a dependência dos homens, e a adesão a esses produtos contribui para a adaptação à sociedade industrial, que tem em sua estrutura elementos de manutenção das condições existentes. Pode-se dizer que a indústria cultural não está preocupada com a formação, segundo os frankfurtianos, mas com a própria ideologia, pois representa, de forma camuflada, as relações sociais.

A ideologia, por sua vez, apresenta-se como mentira manifesta, e os homens adaptam-se a ela, mas ao mesmo tempo enxergam através dela. Esse processo vai deixando marcas de sofrimento, que são resultado de uma falsa formação que impede a constituição do indivíduo, mesmo considerando que as condições objetivas para a sua liberdade já estejam presentes.

Esse processo adaptativo leva a sociedade a uma inércia.

[...] hoje, o homem adapta-se às condições dadas em nome do realismo. Os Indivíduos sentem-se, desde o começo, peças de um jogo e ficam tranqüilos. Mas, como a ideologia já não garante coisa alguma, salvo que as coisas são o que são, até a sua inverdade específica se reduz ao pobre axioma de que não poderiam ser diferentes do que são. Os homens adaptam-se a 
essa mentira, mas, ao mesmo tempo, enxergam através do seu manto. [...] a ideologia e a realidade correm uma para a outra; porque a realidade dada, a falta de outra ideologia mais convincente, converte-se em ideologia de si mesma, bastaria ao espírito um pequeno esforço para se livrar do manto dessa aparência onipotente, quase sem sacrifício algum. Mas esse esforço parece ser o mais custoso de todos. (AdORNO; HorKHEIMER, 1973, p. 203)

A "mentira manifesta" cristaliza-se, fazendo os indivíduos acreditarem em algo que não se deveria crer. O desenvolvimento da ideologia ocorre com base em uma sociedade marcada pelo capital, pelas relações de produção e por desejos dos indivíduos, tendo o medo como mediador. Segundo Adorno (1986, p. 46), a compreensão do medo, do seu encadeamento histórico no processo de dominação, é decisiva para apontar os fatores subjetivos que alicerçam a "irracionalidade do sistema racional". O medo surge diante da possibilidade de diferenciação diante do mundo indiferenciado. Há dois tipos básicos de medo: um, de ser destruído, e outro, a ameaça de não pertencer à unidade social. E esses medos acabam por impedir a autonomia dos homens, e sem a autonomia que os diferencie a dominação instalase. A dominação ocorre contra os interesses racionais, e a irracionalidade objetiva que se apresenta se manifesta na "psicologia do sujeito cativo" (ADORNo, 1986, p. 46), nos homens que se mantêm como prisioneiros, mesmo estando postas as condições para a liberdade.

Os homens passam a reproduzir os papéis sociais, ao invés de apropriar-se deles, pois a capacidade de apropriação (tornar algo como próprio) está afetada. Através do processo de "socialização total" (ADORNo; HoRKHEIMER, 1973, p. 40) a reprodução é efetivada, embora esse processo também traga o risco de sua destruição.

O simples fato de que a civilização não alcança hoje os homens de uma forma imediata, como seres da natureza [...], implica que a socialização total se lhes apresentará, forçosamente, cercada de sacrifícios, que eles não estão dispostos a aceitar, nem são capazes disso. Não menos importante foi a visão profunda de Freud, ao estabelecer que, como as renúncias cada vez maiores impostas aos instintos não encontram uma saída equivalente nas 
compensações pelas quais o ego as aceita, os instintos são assim reprimidos, não têm outro caminho senão o da rebelião. A socialização gera o potencial da sua própria destruição, não só na esfera objetiva mas também subjetiva. (HoRKHEIMER; ADORNO, 1973, p. 41)

Adorno (1995, p. 122) afirma que a pressão geral sobre o particular tem a tendência de destruir tanto o particular e o individual quanto o potencial de resistência. Dentro desse contexto, "o sonho da formação [...] se falseia em uma apologia do mundo" (ADORNo, 1972, p. 147). A formação já não existe desde o momento em que ela ocorre, pois, segundo esse autor, sua ruína já está incluída na sua origem, a sua finalidade está comprometida pelos seus meios, portanto, "em sua origem está incluída teleologicamente sua ruína” (ADORNo, 1972, p. 154-155).

Lembrando que a formação é a apropriação subjetiva da cultura e que esta impede a constituição de um indivíduo autônomo, a adesão do indivíduo à ideologia, mentira manifesta, acaba por ser facilitada. Nota-se, portanto, que a sociedade burguesa privou a formação de sua base, surgindo assim a pseudoformação, que é "a integração e a domesticação do indivíduo [...] a pseudoformação impede o pensamento" (СRоснік, 2000, p. 163). E, dessa forma, dificulta ao indivíduo apropriar-se dos bens produzidos historicamente; dificultalhe a compreensão da realidade e da irracionalidade a que se deixa submeter, impedindo-o, assim, de ver as condições de liberdade e de felicidade que já estão presentes. Esse fato é decorrente da deficiência de sua formação, ou seja, há uma "perda da capacidade de fazer experiências formativas" (MAAR. In: ADORNo, 1995, p. 26).

Tendo em vista as reflexões anteriores e que uma instituição escolar (de qualquer nível) não constitui um fim em si mesma, pois está inserida no contexto global da formação cultural, ou melhor, da pseudoformação, questiona-se, como profissional da educação, o objetivo da formação, da educação, em especial, da educação formal.

Adorno (1995, p. 141) afirma que a sua concepção inicial de educação não estaria ligada nem à modelagem de pessoas (ninguém tem o direito de modelar outra pessoa com base em algo externo a 
ela) nem à simples transmissão de conhecimento. A educação teria como responsabilidade "a produção de uma consciência verdadeira". Isto seria inclusive da maior importância política" (ADORNO, 1995, p. 141).

No entanto, como produzir uma consciência verdadeira se a pseudoformação, como já foi dito anteriormente, passou a ser a forma dominante da consciência, baseando-se na onipresença de um espírito alienado, decorrente de uma estrutura de dominação? E qual seria o papel, a função do professor dentro desse processo?

Adorno, em sua obra, principalmente nos ensaios direcionados à formação e à educação, dá suportes e indicações para uma reflexão no sentido desse questionamento. Essa reflexão, acredita-se, perpassará por toda a vida acadêmica e profissional.

No ensaio "Educação - para quê?", Adorno (1995, p. 139) diz que seria importante discutir "para onde a educação deve conduzir". Segundo ele, houve um tempo em que os conceitos de educação e formação

[...] como dizia Hegel, eram substanciais, compreensíveis por si mesmos a partir de uma totalidade de uma cultura [...] No instante em que indagamos: Educação - para quêe, onde esse para quê não é mais compreensível por si mesmo, ingenuamente presente, tudo se torna inseguro e requer reflexões complicadas, sobretudo uma vez perdido este para quê, ele não pode ser simplesmente restituído por um ato de vontade erigindo um objetivo educacional a partir do seu exterior. (ADORNO, 1995, 141)

Essa perda de sentido do processo educacional é decorrente da barbarização produzida pelas relações irracionais existentes em nossa sociedade. A barbarização é contrastante à formação cultural, pois afeta a capacidade de os indivíduos realizarem experiências formativas.

A capacidade da aptidão à experiência consistiria essencialmente na conscientização e, dessa forma, na dissolução desses mecanismos de repressão e dessas formações reativas que deformam nas próprias pessoas sua aptidão à experiência. (ADORNo, 1995, p. 150) 
Os fenômenos da alienação - que impedem os homens de serem aptos à experiência - trazem, em seu bojo, aspectos subjetivos e objetivos, conscientes e inconscientes. Assim, questionamentos da "psicologia profunda" (p. 149) são fundamentais na reflexão educacional, no sentido de promover o esclarecimento, ou seja, a conscientização do processo de dominação e barbarização presentes na sociedade. Segundo Adorno, "A educação tem sentido unicamente como dirigida a uma auto-reflexão crítica" (p. 121).

A emancipação, diz ele, "precisa ser inserida no pensamento e também na prática educacional" (1995, p. 143), porém aponta que a própria organização do nosso mundo, a ideologia dominante e o processo de adaptação gerado pela sociedade são problemas para a emancipação.

A educação seria impotente e ideológica se ignorasse o objetivo de adaptação e não preparasse os homens para se orientarem no mundo. Porém ela seria igualmente questionável se ficasse nisto, produzindo nada além de well adjusted people, pessoas bem ajustadas, em consequiência do que a situação existente se impõe precisamente no que tem de pior. Nestes termos, desde o início existe no conceito de educação para a consciência e para a racionalidade uma ambigüidade. Talvez não seja possível superála no existente, mas certamente não podemos nos desviar dela. (AdORNo, 1995, p. 143-144)

Assim, só se pode pensar uma educação que seja direcionada para a emancipação e, nesse sentido, ela seria um processo de esclarecimento em busca permanente de superação da ideologia, do sujeito cativo, desenvolvendo a capacidade de os indivíduos realizarem experiências, as quais são pressupostos para os mesmos se tornarem autônomos. Vislumbram, dessa forma, mecanismos de resistência à barbarização presentes na sociedade, pois "a educação para a experiência é idêntica à educação para a emancipação" (ADORNo, 1995, p. 151).

Segundo ele,

[...] a única concretização efetiva da emancipação consiste em que aquelas poucas pessoas interessadas nessa direção orientem 
toda a sua energia para que a educação seja uma educação para a contradição e para a resistência. (ADORNO, 1995, p. 182-183)

E a emancipação se concretiza, só e somente só, se ela for elaborada em todos os planos de nossa vida.

Baseando-se nessa perspectiva de educação para a contradição e para a resistência, como o professor situar-se-ia? Qual a sua função nesse processo? A reflexão do papel do professor nesse contexto é algo muito instigante. Adorno afirma que quem tem deficiência em sua formação cultural, ou seja, que não tenha à

[...] disposição aberta, a capacidade de se abrir a elementos do espírito, apropriando-os de modo produtivo na consciência, em vez de se ocupar com os mesmos unicamente para aprender [...] seria melhor que [...] não se dedicasse a ensinar. Ele [...] dará prosseguimento a esta deficiência nos alunos". (1995, p. 64)

Tendo em vista que somos professores pseudoformados, como sair dessa armadilha?

Nesse sentido, além de toda a compreensão do processo de dominação presente na sociedade, faz-se necessário clarear os tabus ${ }^{3}$ que cercam o magistério, a profissão de ensinar, pois uma escola sem professores não tem sentido. Mas este, o professor, tem de ter clareza quanto à sua tarefa principal. Segundo Adorno (1995, p. 177), "consiste em se tornar supérfluo" que seu aluno caminhe rumo à autonomia. Para isso, a identificação do professor com o conhecimento é básica, fundamental, pois facilitaria a identificação, também do aluno, com o processo de produção do conhecimento, possibilitando, dessa forma, a liberdade do aluno, a sua independência no contexto de suas experiências formativas, fato esse essencial para a constituição de uma verdadeira formação cultural, que só tem condições de existir com indivíduos autônomos.

O aprofundamento na compreensão dos nexos da profissão de ensinar direcionada a uma educação emancipatória é fundamental nas discussões e reflexões relativas à formação de professores, pois, pelo que vem se delineando atualmente, o professor, entre outras coisas, vem convertendo-se em um vendedor de conhecimento, o que "nesses termos reduz o intelecto a um mero valor de troca, o que 
é tão problemático como o é qualquer progresso no seio do existente" (Adorno, 1995, p. 105).

Logo, ele se torna um instrumento de manutenção e reprodução da barbarização. Portanto, a reflexão sobre a função do professor torna-se fundamental, na perspectiva de esclarecer as contradições e, conseqüentemente, as dificuldades encontradas por ele, no desenvolvimento de ações educacionais que, efetivamente, desenvolvam em seus alunos capacidades de experiências formativas, que lhes possibilitem esclarecer as contradições no mundo em que vivemos e resistir ao processo irracional da barbarização, cada vez mais refinada, e que banaliza cada dia mais a vida humana.

Enfim, o papel dos professores é, pelo menos, tentar barrar o processo de barbarização presente em nossa cultura. Só a desbarbarização da sociedade poderá salvar o ser humano, a sociedade, tendo em vista que a busca de elementos concretos que possam subsidiar a luta contra a barbarização deve constantemente refletir esse processo. Isso é importante para a conquista da própria formação cultural dos professores, para a sua constituição como indivíduos autônomos e, conseqüentemente, como sujeitos. Com base nessa situação, as possibilidades para se desenvolverem mecanismos objetivos e subjetivos - no sentido de se resistir a todo esse processo de dominação que desfigura a humanidade - poderão surgir. Assim, o professor, talvez utopicamente, terá melhores condições para possibilitar aos seus alunos o desenvolvimento de experiências que gerem capacidades intelectuais de compreensão das contradições e de resistência às condições desumanas impostas pela sociedade, logo à produção de uma consciência verdadeira.

Portanto, é importante pesquisar e refletir acerca do papel do professor, sua formação e suas condições de atuação, com a finalidade de verificar as suas possibilidades, os seus obstáculos, os seus impedimentos de constituição como indivíduo autônomo. É importante verificar também como ele está lidando com o processo de dominação presente em todas as esferas da sociedade, pois é pela resistência ou não a esse processo que ele cumprirá o seu papel de tentar conter a barbárie e proporcionar aos alunos experiências formativas que lhes dêem o mínimo de condições para desenvolver uma consciência 
verdadeira. Em decorrência disso, é essencial estar sempre pesquisando sobre os professores, pois assim se estará repensando a sua formação em geral, como também a nossa própria formação como indivíduos e professores universitários e, conseqüentemente, visualizar as possibilidades objetivas e subjetivas de resistências no contexto das universidades.

\section{ABSTRACT}

The aim of this article is to reflect upon the education based on the emancipatory formation, having the Frankfurt School/ Critical Theory of Society as a theoretical basis. The burgeois society impeded the cultural formation of its individual, ie, the subjective appropriation of the culture, hindering the constitution of an autonomous and emancipated individual. As a result, a pseudoformation emerged, a loss of capacity to have formative experience. Consequently, the education would have as responsability the production of a true conscience, of a critical self-reflection. Thus, a reflection to contradiction and to endurance. The reflection and discussion of the cultural formation of teachers are essencial to the search of an Emancipatory Education.

Keywords: formation, culture, pseudoformation, experience, individual, autonomous, teachers.

\section{NOTAS}

1. Entre os estudiosos da teoria frankfurtiana, existe uma parcela que utiliza o termo semicultura/semiformação e outra pseudocultura/pseudoformação; não se fará essa discussão neste trabalho; o uso dos termos semicultura/semiformação só aparecerão em citações, quando utilizados pelo autor citado.

2. "Indústria cultural", termo cunhado por Adorno na década de 1950 que ilumina as diversas faces da relação entre economia e cultura no mundo contemporâneo. Meios característicos: rádio, televisão, cinema, revistas etc. "O cinema e o rádio não precisam mais se apresentar como arte. A verdade de que não passam de um negócio [...] utilizam como ideologia [...] Eles mesmo se definem como indústrias" (Adorno, 1985, p. 114). 
3. Os textos "A filosofia e os professores" e "Tabus acerca do magistério" são um bom começo para essa discussão (AdORNo, 1995, p. 51-75 e 97118). A psicologia profunda/psicanálise também possui elementos fundamentais nesse sentido.

\section{REFERÊNCIAS}

ADORNO, T. W.; HORKHEIMER, M. Dialética do esclarecimento: fragmentos filosóficos. Rio de Janeiro: Jorge Zahar, 1985.

Temas básicos de sociologia. São Paulo: Cultrix/USP, 1973.

ADORNO,T. W. Acerca de la relación entre sociologia y psicologia. In: JENSEN, H. Teoria crítica del sujeito. Buenos Aires: Siglo XXI, 1986, p. 3683.

Actualidad de la filosofia. Barcelona/Espãna: Paidós Ibéria, 1991.

Educação e emancipação. Tradução Wolfgang Leo Maar. Rio de Janeiro: Paze Terra, 1995.

La televisión como ideología. In: . Intervenciones. Caracas: Monte Ávila Editores, 1969, p. 75-89.

Mínima moralia. São Paulo: Ática, 1993.

Teoria de la seudocultura. In: Filosofia y superstición. Madrid: Alianza Editorial, 1972, p. 141-174.

CROCHIK, J. L. La pseudoformación y la conciencia ilusionada. In: Revista Educação 26 y Pedagogia 27. v. VII. Colômbia: Universidad de Antioquia/ Faculdade de Educación, 2000.

FREUD, S. O mal-estar na civilização. In: Obras psicológicas. Rio de Janeiro: Imago, V - XXI, 1980, p. 81-178.

MAAR, W. L. À guisa de introdução: Adorno e a experiência formativa. In: ADORNO T. W. Educação e emancipação. Rio de Janeiro: Paz e Terra, 1995.

MATOS, O. C. F. A Escola de Frankfurt: luzes e sombras do iluminismo. São Paulo, s.n., 1993.

RECEBIDO EM 12/02/2003 